\title{
Elementos fundamentales para la historia conceptual de la educación neogranadina: 1767-1853 ${ }^{1}$
}

\author{
Fundamental Elements for \\ the Conceptual History of Education \\ in the New Granada, 1767-1853
}

\section{John Jairo Cárdenas-Herrera \\ Centro de Estudios Sociales, \\ Universidad Nacional de Colombia \\ jjcardenash@unal.edu.co}

\begin{abstract}
Resumen
Este artículo tiene como objetivo proponer algunos elementos fundamentales para la historia conceptual de la educación en la Nueva Granada entre 1767 y 1853. Los puntos centrales de esta historia son la descripción y el análisis de las prácticas educativas que se dieron en el proceso de transición de colonia a república y de vasallo a ciudadano.

La metodología a seguir se basa en postulados de la histórica conceptual, la cual establece que los conceptos son concentrados de experiencia histórica, de contenidos polisémicos y usos variados, signo y factor de la acción social. Los conceptos a describir y analizar serán los de escuela de primeras letras, educación pública e instrucción pública.

La principal conclusión del trabajo es que la educación se usó como estrategia, y la escuela de primeras letras, como táctica dentro del proceso de invención de la república y constitución del ciudadano en la Nueva Granada durante la primera mitad del siglo XIX.
\end{abstract}

Palabras clave: escuela de primeras letras, educación pública, instrucción pública, historia conceptual, república, Nueva Granada.

\footnotetext{
${ }^{1}$ Este artículo es una versión adaptada del capítulo dos de la tesis para obtener el título de doctor en ciencias humanas y sociales, que se titula "Educación, república y ciudadanía. La escuela de primeras letras en la Provincia de Bogotá: 1819-1853" (Cárdenas-Herrera, 2017).
} 


\section{Abstract}

This article's main objective is to propose some fundamental elements for the conceptual history of education in the New Granada between 1767 and 1853. The central point of this history is the description and analysis of the educative practices that occurred in the transition process from Colony to Republic and the constitution of the citizen. The methodology to be followed is based on the postulates of conceptual history, which establishes that concepts are concentrations of historical experience, with polysemic content and varied uses, and are a sign and factor of social action. The concepts to be described and analyzed will be those of elementary schools (First Letters Schools or escuelas de primeras letras in Spanish), public education and public instruction. The main conclusion of the work is that education was used as a strategy, and First Letters Schools as a tactic, within the process of invention of the Republic and constitution of the citizen in New Granada during the first half of the nineteenth century.

Keywords: First Letters Schools, public education, public instruction, conceptual history, Republic, New Granada.

\section{Conceptos fundamentales del lenguaje educativo neogranadino}

El objetivo general del presente artículo es comprender históricamente el lenguaje educativo republicano de la Nueva Granada; esto es, describir y comprender el uso y el significado de los conceptos fundamentales que conformaron dicho lenguaje, a este trabajo se le ha querido llamar historia conceptual de la educación neogranadina, en adelante HCEN. La comprensión histórica del lenguaje $e^{2}$ educativo, a través del estudio de conceptos fundamentales, permite acceder a las prácticas, a las experiencias y a las expectativas que los habitantes de la Nueva Granada, de la primera mitad del siglo XIX, tuvieron con respecto al rol de la educación en el proceso de invención de la república y constitución del ciudadano.

Estas prácticas, experiencias y expectativas llegan a través de diversos registros como leyes, decretos, informes de funcionarios, así como de cuadros de costumbres, manuales de

\footnotetext{
${ }^{2}$ Los lenguajes muy institucionalizados, como el educativo, son usados por "[...] comunidades concretas en el ejercicio de su profesión y que articulan sus actividades y prácticas institucionales en torno a ellos"; sin embargo, éstos se emplearon y modificaron por legos y seglares "[...] para aplicarlos a fines no relacionados con la profesión [valiéndose de] idiomas de diversas fuentes hasta el punto de modificar los efectos que producen [formulando] retóricas hostiles a otros lenguajes que querían imponérseles" (Pocock, 2011: 108). Así, los lenguajes gubernamentales resultaron más fáciles de asir, pues sus registros son más evidentes; el reto es seguirle el rastro al uso de éstos por parte de las comunidades parroquiales que pudieron usarlos en el sentido que el gobierno republicano pretendía, o bien, los adaptaron a sus necesidades particulares, o bien, pudieron repelerlos y crear otros.
} 
enseñanza, catecismos, periódicos, diarios y biografías, en donde se puede asir el lenguaje educativo que se usaba y en particular, los conceptos ${ }^{3}$ a través de los cuales se "[...] organizaba la experiencia y el lenguaje educativos de ciertos sectores con capacidad de definición cultural" (Caruso, 2010: 40). De la red conceptual que conformaba el lenguaje educativo neogranadino, se eligieron los conceptos fundamentales de educación pública, instrucción pública y escuela de primeras letras, ya que "[...] vendrían a ser algo así como 'concentrados de experiencia histórica' y, al mismo tiempo, "dispositivos de anticipación de las experiencias posibles" (Fernández, 2014: 27); es decir, éstos permiten comprender tanto el campo de experiencia como el horizonte de expectativas que los neogranadinos tenían en la primera mitad del siglo XIX con respecto a la educación; además, resultan esenciales, porque:

... cada concepto indica estabilidad o cambio, y que la división entre pasado y futuro está internamente contenida en el mismo, porque la mudanza o evolución conceptual significa naturalmente la pérdida de una parte de la carga de pasado que cada concepto internamente conlleva y el aumento correlativo de sus expectativas de futuro ... (Fernández Sebastián y Fuentes, 2006: 7).

La educación cumplió, en el marco del proceso de invención republicana neogranadina, una función más política, que de tipo cognitiva o pedagógica, ésta es, precisamente, la nueva experiencia que se pretende describir y comprender. En este sentido, metodológicamente hablando, el componente diacrónico de la HCEN se rompe con la sincronía de los movimientos políticos que cambiaron la experiencia y la expectativa en torno al rol de la educación en el proceso de invención de la república y la constitución del ciudadano. Además, la HCEN permite establecer el horizonte semántico, el campo de posibilidades lingüísticas que los neogranadinos tuvieron, que es un ejercicio de restitución histórica en donde el presente y el futuro del pasado se comprenden mejor.

${ }^{3}$ Dice Koselleck (1993: 116-118) que todo concepto es una palabra, pero no toda palabra se convierte en concepto. Los conceptos sincrónicamente tematizan situaciones, y diacrónicamente, tematizan su modificación: "Los conceptos sociales y políticos contienen una concreta pretensión de generalidad y son siempre polisémicos [...] una palabra se convierte en concepto si la totalidad de un contexto de experiencia y significado sociopolítico, en el que se usa y para el que se usa una palabra, pasa a formar parte globalmente de esa única palabra. [...] Los conceptos son, pues, concentrados de muchos contenidos significativos [...] Un concepto reúne la pluraridad de la experiencia histórica y una suma de relaciones objetivas en un contexto que, como tal, sólo está dado y se hace experimentable por el concepto. [...] Un concepto no es sólo indicador de los contextos que engloba, también es un factor suyo. Con cada concepto se establecen determinados horizontes, pero también límites para la experiencia posible y para la teoría concebible". 
Los conceptos fundamentales escogidos tienen un componente semántico, ${ }^{4}$ sino también uno pragmático, ${ }^{5}$ la HCEN que se está proponiendo, precisamente, acude al estudio de las prácticas para asir a ambos. Dentro de la HCEN, se asume que los conceptos son vectores ${ }^{6}$ de la vida social que permiten acceder a las prácticas, a las expectativas y a las experiencias de los sujetos históricos; es decir, tanto a los futuros posibles que los agentes tenían en mente, cuando realizaban una acción social, como a lo que de inmediato ellos hicieron; lo primero remite a los horizontes de expectativas, mientras que lo segundo refiere el campo de las prácticas y las experiencias. El horizonte de expectativas comprende los futuros posibles que pudieron ser y no fueron; es un conjunto de disposiciones normativas que intentaron establecer un estado de cosas que no necesariamente pasaron de lo normativo a lo positivo. Por su parte, el campo de experiencias constituye lo positivo, el conjunto de prácticas, de acciones realizadas.

\section{Los conceptos de educación pública e instrucción pública en la Nueva Granada a finales del siglo XVIII y comienzos del XIX}

La Real Academia de la Lengua Española ha publicado 23 ediciones de su Diccionario de la Lengua Española desde 1780, éste permite conocer los cambios y las permanencias de los significados de las palabras en castellano. Para comprender las prácticas educativas que la población neogranadina seguía a finales del siglo XVIII y percibir las transformaciones que sufrieron con la irrupción de la república en el siglo XIX — proceso de transición de colonia a república- es necesario establecer el uso y el significado de los conceptos educación pública e instrucción pública, que se referían al proceso educativo en el periodo en mención; para ello, se ha decidido indagar sobre los usos y los sentidos del adjetivo que es común denominador a las dos palabras: público.

${ }^{4}$ La semántica es la disciplina que se encarga de analizar el significado de las palabras.

${ }^{5}$ La pragmática es "la disciplina que analiza los fenómenos léxicos y gramaticales en función de las intenciones de los interlocutores [...] Corresponde también a esta disciplina analizar las formas en que se transmiten [uso] y se interpretan [sentido] las informaciones verbales no codificadas lingüísticamente, así como la posible pertinencia lingüística de otros datos, como los relativos a la identificación de los interlocutores o al momento y al lugar en que se emiten los mensajes. [...] la pragmática estudia el uso de los recursos idiomáticos..." (RAE, 2009: 4 y 5).

${ }^{6}$ El Diccionario de la Lengua Española, DLAE, da dos acepciones de vector que resultan sugerentes para el estudio de las prácticas: "1. Agente que transporta algo de un lugar a otro" y "2. Toda acción proyectiva que tiene cualidad e intensidad variables". Se usa el vocablo vector para significar la capacidad de las prácticas de transportar sentidos y acciones, en este caso, del pasado al presente; además, los vectores sirven como acciones que proyectan futuros posibles del pasado (horizonte de expectativas). 


\title{
El concepto de público en el proceso de transición de colonia a república
}

Entre los principales conceptos que formaron parte tanto del proceso de invención de la república como de la constitución del ciudadano, se encuentran los de ilustración, instrucción pública, educación, escuela de primeras letras, república y ciudadanía. El cambio en el uso y el sentido de dichos conceptos es signo del promisorio horizonte de expectativas que se abrió a los neogranadinos de la primera mitad del siglo XIX y su comprensión sólo es posible a través de un análisis histórico-conceptual (Koselleck, 2012). Para comprender los sintagmas de educación pública, instrucción pública o escuela de primeras letras, es necesario adentrarse en el entorno enunciativo, en la gramática del momento en el que éstos emergieron, ya que los usos y los sentidos de los conceptos son dinámicos, y no estáticos, índice y factor de los cambios que la sociedad sufre en su cotidianidad.

Un vocablo que se utilizó mucho en el campo educativo republicano fue el de público, pero éste sufrió una importante transformación en su uso y significado desde la colonia, cuando se entendía como el conjunto de vecinos concretos que conformaban una comunidad. El público no era un ente abstracto, sino que tenía nombre y apellido y podía demandar derechos a través de las corporaciones de las cuales formaba parte; esta situación cambió a finales del siglo XVIII, cuando, debido a la acentuación de las reformas borbónicas ${ }^{7}$ que propendían, entre otras cosas, por la implantación de un gobierno económico (Cárdenas-Herrera, 2015b), el vocablo empezó a volverse más abstracto en cuanto entidad general que debía ser favorecida por las actuaciones de las corporaciones. Así, aparecieron los sintagmas utilidad pública, que hacía referencia a los intereses económicos de la corona borbónica; e instrucción pública, que se usó en uno de los últimos documentos imperiales, expedidos por Carlos III en 1778:

\begin{abstract}
Instrucción hecha de orden del Rey nuestro señor para que los Virreyes, Gobernadores, Corregidores, Alcaldes Mayores e Intendentes de provincias en todos los dominios de su Majestad puedan hacer escoger, preparar y enviar a Madrid todas las producciones curiosas de naturaleza que se encontraren en las tierras y pueblos de sus distritos, a fin de que se coloque en el real gabinete de Historia Natural que su Majestad a establecido en esta Corte para beneficio e instrucción pública. ${ }^{8}$
\end{abstract}

El concepto público también se usó al lado del de universidad, diez años antes de la comunicación imperial citada, el 19 de mayo de 1768, uno después de la expulsión de los jesuitas de

\footnotetext{
${ }^{7}$ Proceso ocurrido, sobre todo, desde el reinado de Carlos III en España (1759-1788).

${ }^{8}$ Las cursivas son mías.
} 
tierras americanas. El fiscal, Francisco Antonio Moreno y Escandón, ${ }^{9}$ como miembro de la Junta de Temporalidades encargada de la administración de los bienes de los jesuitas, se ocupó de redactó una reforma educativa que contemplaba la transformación de los colegios de Santa Fe en universidades públicas, financiadas por la corona, con un gobierno autónomo y civil y con un nuevo plan de estudios, lo cual sólo se logró hasta de 1774. Este proyecto se financió con los fondos confiscados a la Comunidad de Jesús, a los que en las cuentas de la Real Hacienda se denominaron "ramo de temporalidades".

El vocablo público no sólo formó parte de sintagmas como educación pública o universidad pública; a finales del siglo XVIII, era parte de otro que implicó grandes transformaciones para la sociedad neogranadina: el sintagma opinión pública. Por esta época, en la Nueva Granada, se fundaron publicaciones periódicas como El Papel Periódico de la Ciudad de Bogotá, dirigido por Manuel del Socorro Rodríguez y financiado por el virrey, Ezpeleta, en 1791; El Correo Curioso, empresa particular presidida por Jorge Tadeo Lozano, y publicado a lo largo de 1801; y el Semanario de la Nueva Granada, dirigido por Francisco José de Caldas, iniciado en 1807 y finalizado con los levantamientos de Santa Fe en 1810. Estos periódicos tenían como objeto central poner en público noticias, saberes, debates, descubrimientos, técnicas, polémicas, etc., lo cual abrió paso a un nuevo tipo de sociabilidad que ponía en escena un conjunto de tácticas para hacer circular las ideas. Este proceso histórico ha sido objeto de estudio en los últimos años por investigadores que quieren comprender la cultura política de finales del siglo XVIII y comienzos del XIX, a través de un acercamiento al funcionamiento de la opinión pública, entendida como "una configuración históricamente determinada de los modos de publicidad existentes en una sociedad" (Ortega y Chaparro, 2012: 22), y la publicidad, como "un conjunto de medios para divulgar, el acto de divulgación o el lugar en que las cosas adquieren la calidad de público...".

El sintagma opinión pública apareció en Occidente entre 1750 y 1850, y en el espacio iberoamericano hizo también carrera; Feijoo (1749) hablaba de la voz del pueblo, para referirse a la opinión de la mayoría, en términos de individuos en posesión de razón. En las décadas de los años setenta y ochenta del siglo XVIII, se empezó a usar el sintagma opinión pública, y ya en los años noventa fue temido por funcionarios y regidores que se preguntaban

\footnotetext{
${ }^{9}$ Francisco Moreno y Escandón redactó y radicó ante la Junta de Temporalidades de Santa Fe su "Proyecto para el establecimiento en la ciudad de Santafé de Bogotá de una Universidad de Estudios Generales, presentado a la Junta General de Aplicaciones por el doctor don Francisco Antonio Moreno y Escandón, Fiscal Protector de Indios, de la Real Audiencia del Nuevo Reino de Granada", (véase Hernández de Alba, 1768: 26-35). La Junta de Temporalidades envió el proyecto a Madrid el 19 de mayo de 1768; el Consejo Real lo discutió y aprobó el 9 de julio de 1769. El Consejo Real decidió establecer en la capital del virreinato una universidad pública; esta decisión se comunicó a la Junta Superior de Aplicaciones de Santa Fe a través de una orden del conde de Aranda, fechada el 22 de diciembre de 1770. El 4 de diciembre de 1771, la Junta suscribió un acta en la cual aprobaba el Plan de Aplicaciones del fiscal, y particularmente, su proyecto de universidad pública (Junta de Temporalidades) que debería ser financiada con recursos del fondo de temporalidades.
} 
preocupados "¿De dónde le viene a la opinión pública este espantoso influjo que tiene en la suerte de las sociedades?" (Jovellanos, 1790: 15). De esta forma, a comienzos del siglo XIX, la acepción, el sentido y el uso del concepto público eran claramente más abstractos y hacían alusión a los destinatarios de los periódicos y escritos que las élites circulaban en la sociedad en forma de impresos, ejemplo de ello es el nombre de uno de los rotativos neogranadinos más representativos de esos años: el Aviso al público, publicado desde 1810 en Santa Fe.

Luego del apresamiento de Fernando VII en 1808, ocurrió un fenómeno muy interesante en la Nueva Granada, estudiado por Francisco Ortega en un trabajo de historia conceptual de la palabra pueblo, en donde muestra que, a partir de esta fecha, los sentidos y los usos de los vocablos pueblo y público empezaron a solaparse, debido a que la soberanía había retornado del rey al pueblo. Así, tras la ausencia del rey, el pueblo se convirtió en fuente legítima de soberanía y era a quien iba dirigida la opinión pública, ${ }^{10}$ esta última tenía, justamente, la función de "fijar la opinión del pueblo" (Ortega et al., 2013: 18).

La noción de pueblo soberano sólo fungió como idea movilizadora en los primeros años de las guerras de independencia pues, luego de promulgada la Constitución de 1821, el pueblo dejó de verse como fuente de soberanía y se convirtió en "objeto de la cuestión social" (Ortega et al., 2013: 21), en objeto de educación moral y de gobierno por parte de la república. Así, las autoridades republicanas se dieron a sí mismas la misión de "instruir al pueblo idiota”, como fray Diego Padilla (1811: 140), editor del Aviso al público, pregonaba. Esta práctica de instruir al pueblo, que llega a través del lenguaje, muestra la inflexión en el uso y el sentido del sintagma escuela pública por parte del gobierno republicano; la escuela ya no era "pública" por ser financiada por fondos públicos de los vecinos, sino por tener como su objeto al pueblo, transformación que, a su vez, da cuenta de otra mucho mayor: el paso de la ilustración del público a la educación pública.

\section{De la ilustración del público a la educación pública}

En 1780, según el diccionario de la Real Academia Española, por educación se entendía "La crianza, enseñanza y doctrina con que se educan los niños en sus primeros años"; para 1817, se generó una pequeña inflexión "La crianza, enseñanza y doctrina que se da á los niños y jóvenes". Pese a la similitud de las definiciones, existe una continuidad y dos rupturas que señalan nuevos usos y sentidos del concepto de educación en el proceso de transición de colonia a república:

\footnotetext{
${ }^{10}$ Este fenómeno histórico está asociado a la emergencia del pueblo como sujeto político y como sujeto de la política, esto es, el pueblo se hace agente y sujeto de la política.
} 
1. Continuidad. En ambas definiciones, la educación se concebía como un proceso dirigido a conseguir la crianza, la enseñanza y la doctrina, acciones que se pueden relacionar con la moral, el saber y la fe que, tanto en la colonia como en la república, constituyeron las bases fundamentales del proceso educativo.

2. Ruptura 1. La educación — crianza, enseñanza y doctrina - era, en 1780, un asunto de los niños mismos - con el que se educan los niños- o, por lo menos, de sus padres o pastores; mientras que en 1817, ya no constituía un proceso autónomo con el cual se lograba la crianza, la enseñanza y la doctrina, sino algo que se daba; es decir, pasó de ser un conjunto de acciones con el que se educan los protagonistas del proceso educativo: los niños y sus preceptores - padres y pastores - a ser un conjunto de acciones predefinidas, preconcebidas y diseñadas por el gobierno, se dan a los niños.

3. Ruptura 2. En 1780, la educación estaba dirigida a los niños en sus primeros años; mientras que en 1817, se eliminó lo de "en sus primeros años" y se orientó a los jóvenes; es decir que, además de un dador y un receptor de la educación, gobierno y niños respectivamente, el espectro de estos últimos se amplió en lo que significó la inclusión, no sólo de la escuela de primeras letras, sino de los colegios, lo cual se constituyó como la educación pública.

A comienzos del siglo XIX, la educación pública se usó como contraconcepto de la educación particular, sin importar si era agenciada por las órdenes religiosas, los cabildos o las parroquias; lo público era un tipo de educación colectiva que se realizaba fuera del ámbito doméstico (Roldán, 2014), y no implicaba una oposición al rol de la iglesia dentro del proceso educativo, sino que apuntaba a señalar la necesidad de sacar a la educación del ámbito familiar.

En el caso particular de la Nueva Granada, con la Constitución de Cundinamarca de 1812, el gobierno republicano se involucró por primera vez en asuntos otrora domésticos, como la educación:

1. El Cuerpo Legislativo tendrá en mucha consideracion, y el Gobierno promoverá con el mayor esmero los establecimientos que miran á esta parte importantisima de la felicidad del Estado.

2. En todos los Poblados deberán establecerse escuelas de primeras letras y dibujo, dotadas competentemente de los fondos á que corresponda, con separacion de los dos sexos.

3. Los objetos de la enseñanza de estas escuelas serán leer, escribir, dibujar, los primeros elementos de la Geometria, y antes que todo, la Doctrina christiana, y las obligaciones y derechos del Ciudadano conforme á la Constitucion (Cundinamarca, 1812: 50). 
Para la Constitución de Cúcuta de 1821, los usos del sintagma educación pública implicaban, cada vez más, un rol protagónico del gobierno republicano ${ }^{11}$ sobre el proceso de enseñanza de los hijos de la patria; ya no sólo se intentaba sacarla del ámbito doméstico, sino también del religioso. Se está aquí ante un punto de inflexión en la HCEN, es decir, se está en presencia de la emergencia de un nuevo campo de intervención gubernamental, uno de administración: la educación pública; sin embargo, en ese momento, el sintagma educación pública no contenía el sentido de financiación gubernamental, ya que podía ser soportada por fondos del gobierno o de particulares; sí implicaba, más bien, un rol de supervisión, inspección, vigilancia y control del gobierno republicano en la educación a través de medidas como:

- Ley sobre establecimiento de escuelas de primeras letras para los niños de ambos sexos de 1822 (El Congreso Jeneral de la República de Colombia, 1822a).

- Ley sobre establecimiento de colejios, ó casas de educación en las provincias, reforma de las constituciones y planes antiguos y formación de otro nuevo uniforme en toda la República de 1822 (El Congreso Jeneral de la República de Colombia, 1822b).

- Ley sobre aplicación a la enseñanza pública de los bienes de conventos menores de 1822 (El Congreso Jeneral de la República de Colombia, 1822c).

- Ley sobre el establecimiento de escuelas de niñas en los conventos de religiosas de 1824 (El Congreso Jeneral de la República de Colombia, 1822d).

- Ley sobre organización y arreglo de la Instrucción Pública de 1826 (Congreso Constitucional de la República de Colombia, 1826).

Luego de la Constitución de 1821, el sintagma educación pública se usó para referir el proceso mediante el cual el pueblo accedió a los conocimientos mínimos que la república demandaba, más que al tipo de financiación o agente que la proveía o soportaba (Roldán, 2014). La palabra pública que acompañaba a la de educación hacía referencia, ya en la república, a una población más abstracta que en la colonia, pero con mayor agencia. El público, en la colonia, tenía nombre y apellido y estaba asentado en un territorio concreto; en la república, era más abstracto; perdió concreción, pero ganó agencia, pues constituía uno de los responsables de la financiación de sectores claves de la sociedad, como por ejemplo las escuelas de primeras letras; y, a su vez, era objeto de política pública en la intención de "educar al pueblo idiota" (Padilla, 1811).

\footnotetext{
${ }^{11}$ En este trabajo no se usaron los vocablos de Estado ni de nación, ya que no forman parte de los conceptos fundamentales de la red conceptual que constituía el repertorio político de la primera mitad del siglo XIX neogranadino. Se emplearon los conceptos de gobierno para referir "Las reglas, pues, con que unos han de gobernar y los otros obedecer"; y gobierno republicano cuando "el pueblo todo, bajo ciertas reglas y leyes fundamentales ejerce la potestad legislativa y confiere la ejecutiva y judiciaria á personas que el mismo pueblo elige por tiempo determinado" (Grau, 1824: 15).
} 
El concepto de educación pública, entendido como el proceso de dotación de los atributos necesarios para que el vasallo colonial se convirtiera en ciudadano republicano, tomó forma con el Plan de Estudios de 1826, promovido e implementado por Francisco de Paula Santander, quién fungía desde 1821 como presidente de la república, mientras Bolívar dirigía la campaña del sur. El Plan de Estudios de Santander ordenaba, entre otras cosas, que la escuela de primeras letras siguiera el método propuesto por Joseph Lancaster en su sistema de enseñanza mutua (Lancaster and Institute, 1821); éste tuvo vigencia hasta 1843, cuando se cambió por uno más apegado a las tradiciones y a la lglesia católica y por considerar que "El régimen escolar de la colonia duró hasta 1826, en que se expidió un plan de estudios, muy justamente censurado, porque atendiendo exclusivamente al desarrollo intelectual, no solamente olvidaba la parte moral, religiosa y disciplinaria, sino que las contrariaba, señalando textos impíos é inmorales"12 (Ospina Rodríguez, 1990: 427).

En los años cuarenta, luego de la Constitución de 1842 y de la reforma educativa promovida e implementada por Mariano Ospina Rodríguez (1990: 424 y 425), ${ }^{13}$ la educación pública era concebida como un proceso encaminado al desarrollo de las facultades intelectuales, físicas y, sobre todo, morales del ciudadano:

Educar es perfeccionar un ser humano desarrollando sus facultades. Las facultades humanas se clasifican reuniéndolas en tres ó más grupos: facultades físicas, intelectuales y morales; algunos subdividen estas últimas en religiosas y morales para facilitar su estudio [...] La educación, pues, puede hacer de un pueblo el tipo más perfecto del género humano, ó la porción más degradada, más envilecida, más digna de desprecio y de execración. Nada, pues tan importante como la educación; porque de ella dependen la grandeza y la felicidad de las nociones ó su miseria y desdicha.

Para uno de los personajes más importantes en la implementación de proyectos educativos republicanos de la primera mitad del siglo XIX, la educación era concebida como un mecanismo de perfeccionamiento individual y social, si se sustentaba sobre sólidas bases morales y religiosas, de las cuales debían encargarse el gobierno y la Iglesia católica:

\footnotetext{
12 Se refería fundamentalmente a los textos de Jeremy Bentham que el Plan de Estudios de 1826 había introducido al sistema educativo de la Nueva Granada.

${ }^{13}$ A él se le atribuye uno de los actos fundacionales del Partido Conservador - uno de los partidos políticos que constituye el sistema bipartidista colombiano- a través de la publicación, en octubre de 1849, en compañía de José Eusebio Caro, del artículo "Declaratoria política", en el periódico, La Civilización - que había fundado con aquél dos meses atrás- al que se le suele relacionar como el programa político del conservadurismo colombiano; además, fue uno de los defensores más aguerridos de la Compañía de Jesús, a la que ayudó a reintroducir al país en 1842 — cuando ejercía como secretario del interior y relaciones exteriores bajo el gobierno de Pedro Alcántara Herrán - con el objeto de posicionarlos como base de su política educativa.
} 
La [educación] escolar, que empieza en la escuela primaria y acaba en la Universidad, y que debe abrazar la educación física, religiosa, moral, intelectual é industrial, es organizada por la ley civil y por la ley disciplinaria eclesiástica; por consiguiente depende de la inteligencia y celo de los que ejercen el poder civil y la autoridad eclesiástica el que esta educación ande bien ó mal (Ospina Rodríguez, 1990: 425 y 426).

La reforma educativa de Ospina duró menos que su antecesora; hasta 1853, cuando la Constitución expedida ese año puso a la educación pública en manos de los estados, entidades político-administrativas regionales que reemplazaron a las provincias e instituyeron un modelo federativo de gobierno.

Cabe mencionar que cuando se usaba el sintagma educación pública, durante la década de los veinte y treinta del siglo XIX, se hacía para referir el proceso educativo, más que el acervo de conocimientos que tenía un individuo, para lo cual se prefería el sintagma instrucción pública; luego, en la década de los cuarenta y hasta 1853, el vocablo educación pública se usó para referir la educación moral del ciudadano, basada en los preceptos de la Iglesia católica. Para tener una clara distinción entre educación pública e instrucción pública, a continuación se revisan los usos y los sentidos de esta última en el proceso de transición de colonia a república.

\section{La instrucción pública}

Como se ha señalado, hacia finales del siglo XVIII, lentamente, el vocablo público se volvió más abstracto; y del bien del público, empezó a desearse el bien público; de la utilidad del público, se pasó a la utilidad pública; de la ilustración del público, se devino en la instrucción pública y en la educación pública; es decir, de un conjunto de vecinos concretos que vivían en una circunscripción territorial, se pasó a una noción de población más abstracta que debía ser objeto de instrucción, de educación.

Ya se vieron los usos y los sentidos de la palabra público y del sintagma educación pública; ahora hay que tratar de comprender las similitudes y las diferencias en los usos y los sentidos de los conceptos de educación pública e instrucción pública en el proceso de transición de colonia a república.

En la literatura especializada contemporánea, a la educación se le puede considerar como institución o como proceso. Entendida como institución, la educación implica concebirla como el conjunto de saberes prácticos e intelectuales que una sociedad posee y preserva; sería también el conjunto de normas, valores y conductas que garantizan la vida social y que, por lo tanto, deben transmitirse; como proceso, es el mecanismo, la forma, la operación práctica a través de la cual estos conjuntos de saberes, normas, valores y conductas son transmitidos y apropiados por la población. 
A finales del siglo XVIII, la palabra instrucción contenía los dos sentidos referidos anteriormente, como proceso y como institución: "[...] como acción, la tarea de enseñar, y como estado, la posesión de un caudal de conocimientos adquiridos" (Roldán, 2014: 72); mientras que el vocablo educación sólo hacía referencia al proceso a través del cual se adquiría un saber en una institución formal, del gobierno o de la Iglesia (Roldán, 2013), refería la labor de enseñanza, y no el conjunto de saberes:

\begin{abstract}
Así, en el léxico de la última década del siglo XVIII y las primeras del XIX las expresiones "instrucción pública" y "educación pública" no son estrictamente sinónimas: "instrucción pública" remite a la instrucción general que posee el pueblo mientras que "educación pública" tiende a referirse a la enseñanza (que para Jovellanos debía ser literaria, física y moral) que se imparte en los establecimientos escolares y no en el ámbito doméstico (Roldán, 2014: 75).
\end{abstract}

En el DRAE de 1780, existen tres acepciones para el vocablo instrucción: la acción de instruir, Instructio, disciplina; se llaman también los documentos, o principios de cualquier ciencia, o doctrina, para el conocimiento y el estudio de ésta, Instructio, documentum; asimismo, se Ilaman aquellas órdenes particulares que se dan alos embajadores y otros ministros, para su dirección y gobierno, en el negociado que se les encarga, Mandatum principis, instructio. Para 1817, el DRAE eliminó dos de las anteriores acepciones y dio la siguiente definición de instrucción: la acción y el efecto de instruir (Real Academia Española).

Para finales del siglo XVIII, el sentido que se le daba a la voz instrucción se solapó con el de educación en cuanto proceso: acción de dotar a un individuo de un conjunto de saberes; en 1817, éste sentido no desapareció, pero se incorporó uno nuevo: el del efecto de dicho proceso, es decir, el caudal, el acervo de conocimientos que el proceso educativo implicaba. Entonces, para los años previos a la irrupción de la república, la instrucción implicaba tanto el proceso educativo como el conjunto de saberes que de éste se obtenía, a nivel individual y a nivel social.

El sintagma instrucción pública se usó en los primeros años de la república neogranadina para referir tanto el proceso educativo como el caudal de conocimientos que un individuo en particular y una sociedad en general poseía. De hecho, una de las primeras tareas del gobierno republicano era "[hacer] los reglamentos necesarios para la averiguación, fomento, mejor administración y conservación de las rentas y edificios destinados á la instrucción pública, todos los cuales presentará al próximo congreso" (El Congreso Jeneral de la República de Colombia, 1822b: 73).

A pesar de tener una doble connotación, era más común usar el sintagma instrucción pública para referir el acervo de conocimientos de una persona o sociedad, que el proceso 
educativo como tal, para el cual comúnmente se empleaba el vocablo educación pública, por lo menos en las primeras décadas de la república.

En los años cuarenta, como consecuencia de la influencia de Mariano Ospina Rodríguez en el campo educativo, la educación moral se posicionó como la base del Plan de Estudios de 1843, que reemplazó al de 1826, promovido por Santander, y el uso y el sentido de los sintagmas educación e instrucción tuvieron variaciones importantes: la educación se asociaba con la moral, lo bueno; y la instrucción, con la ciencia, lo útil "En un Estado como el nuestro, la educación debe ser, ante todo, eminentemente moral y religiosa; y la instrucción, eminentemente científica, profesional é industrial: lo bueno y lo útil juntamente, pero de un modo eficaz, positivo y práctico" (Ospina Rodríguez, 1990: 431).

Por su parte, con el advenimiento de la república, el lugar por antonomasia en donde se realizaba el proceso educativo en el cual operaba la educación y la instrucción pública era la escuela de primeras letras. La educación pública, se entendía como el proceso que permitía la adquisición del acervo mínimo de saberes que un ciudadano republicano, debía poseer, sobre todo, los morales y los cívicos; y la instrucción pública, como el caudal de saberes como tal; pero, ¿qué significaba y cómo se usaba el sintagma escuela de primeras letras en la primera mitad del siglo XIX neogranadino?

\section{La escuela de primeras letras}

Un tema que irrumpió con fuerza con la conmemoración del segundo centenario de las revoluciones hispanoamericanas fue el de la preocupación de la academia por las sociabilidades y las prácticas políticas en el proceso de transición de colonia a república. En este ámbito de investigaciones, se ubica la pregunta por el rol de la educación en general y de la escuela de primeras letras en particular, como parte del proceso de construcción de los proyectos republicanos que siguieron a las independencias hispanoamericanas.

La construcción y la puesta en funcionamiento de más y nuevos espacios de sociabilidad política desde las últimas décadas del régimen colonial propiciaron la potenciación de una esfera pública que encontró nuevos medios de publicidad para poner en circulación tanto nuevos conceptos como nuevos sentidos de algunos ya existentes. De igual forma, también se promovió el surgimiento de nuevos espacios de sociabilidad como cafés, tertulias, periódicos, escuelas, colegios y universidades.

Así, para abordar el problema educativo, en el marco del proceso de transición de colonia a república hispanoamericana, el estudio de los espacios de sociabilidad en donde se gestaron las respuestas de la población a dicho problema es indispensable. Es por esto que, dentro de la HCEN, se apuesta por una comprensión histórica de las prácticas educativas 
escolares, que se dieron en la Nueva Granada entre 1767 y 1853 y que permitieron la transformación del vasallo colonial en ciudadano republicano. De esta forma, la HCEN apunta a caracterizar el campo de emergencia, el entorno en el que la república en construcción instituyó a la escuela de primeras letras, ésta tenía el objetivo central de educar a los hijos de la patria, de dotarlos de los atributos —instrucción - que la república demandaba, uno de los cuales era el conocimiento de los derechos y deberes del ciudadano y la adquisición de una educación moral.

Para saber qué cambió con la escuela de primeras letras republicana, primero se debe hacer un acercamiento a las prácticas educativas del periodo colonial que la precedieron, entre las cuales se deben destacar el rol de la Iglesia católica, de los encomenderos y de algunos agentes privados; luego, se deben considerar las reformas borbónicas en donde la escuela de primeras letras debutó como institución, objeto de regulación del gobierno; finalmente, se debe adentrar en la descripción de la estructura, la composición, el entorno y los mecanismos de funcionamiento de la escuela de primeras letras en el periodo republicano.

\section{La escuela de primeras letras durante el periodo tardo-colonial}

Durante la colonia, la escuela tuvo diversas formas y agentes: doctrinera y monástica para indios; y en manos de comunidades religiosas o agentes privados para españoles y criollos. Las escuelas doctrineras se establecieron en América desde el siglo XVI, para que los indios de las tierras recién descubiertas aprendieran castellano y los preceptos fundamentales de la religión católica; éstas eran regentadas por la Iglesia y financiadas por los encomenderos, a quienes se les obligaba a crear una en cada encomienda. Por su parte, las escuelas monásticas estaban bajo la responsabilidad de las órdenes religiosas establecidas en América y tenían el objetivo de formar a los hijos de españoles y criollos, así como a los de la élite india.

En lo que respecta a la educación elemental o primaria, el sintagma que empezó a usarse a finales del siglo XVIII, en el ámbito hispánico, fue el de primeras letras, que refería el proceso mediante el cual los infantes se acercaban a la lectura y, sobre todo, a la escritura del castellano ${ }^{14}$ en escuelas o casas de educación "El concepto de las "primeras letras» combinaba así viejos elementos, nuevos impulsos y una intervención creciente de la Administración estatal" (Caruso, 2010: 42). De hecho, en el ámbito hispanoamericano, en el periodo que comprende la expulsión de los jesuitas en 1767 y el proceso de construcción republicana de la década de los años treinta del siglo XIX, el sintagma primeras letras fue usado por legisladores, gobernantes y ciudadanía en general para referir el proceso educativo de los niños en su manifestación gubernamentalizada.

\footnotetext{
${ }^{14}$ Para conocer acerca de la importancia de la escritura en los procesos educativos españoles, véase Redondo, 1996.
} 
Marcelo Caruso (2010: 43) revisó varios fondos documentales españoles y encontró que a finales del siglo XVIII la voz primeras letras estaba contenida, con mayor frecuencia, en textos producidos por la corona, que por la Iglesia. Poco a poco, el vocablo se utilizó con mayor regularidad en manuales, libros de texto, informes de escuela y certámenes de evaluación pública, alcanzando su punto máximo en el periodo 1809-1833: "De esta manera, 'primeras letras' puede ser entendido como un concepto de la educación elemental para un periodo determinado y no meramente como un nombre vago y de reminiscencias antiguas para denotar a las escuelas elementales anteriores a la creación del sistema educativo moderno, como sucede frecuentemente en la bibliografía".

Para el caso americano, Caruso (2010) establece que el uso "estatal" del sintagma primeras letras fue muy bajo en los últimos años de la colonia, apareció con alguna frecuencia luego de las independencias y se hizo recurrente hasta después de 1834; es decir, a diferencia de lo sucedido en España, es sólo hasta bien entrado el siglo XIX cuando el sintagma primeras letras empezó a tener un uso frecuente en los impresos americanos; mientras que en España, ya había perdido vigencia y empezaba a desaparecer en este mismo periodo. La publicación de los siguientes textos en la Nueva Granada dan cuenta de lo dicho por Caruso:

1. Cartilla lacónica de las cuatro reglas de aritmética práctica, dedicada por la Escuela de San Carlos a la Audiencia y Chancillería Real de este Nuevo Reino de Granada de Agustín Joseph de Torres (1797), maestro de primeras letras.

2. Catecismo político: arreglado a la constitución de la monarquía española para ilustración del pueblo, instrucción de la juventud y uso de las escuelas de primeras letras (D. J. C, 1812).

3. Catecismo político arreglado a la constitución de la República de Colombia, de 30 de agosto de 1821, para el uso de las escuelas de primeras letras del Departamento de Orinoco (Grau, 1824).

4. Preceptos útiles sobre la conservación de la salud, y la asistencia de los enfermos: mandados imprimir i enseñar en las escuelas de primeras letras de niños de ambos sexos de la Provincia de Bogotá por el Gobernador de ella, Dr. Rufino Cuervo, (Cuervo, 1833).

5. La ortografía fijada en la Nueva Granada. Método perfeccionado de enseñanza para las escuelas de primeras letras (Blanc, 1833).

6. Compendio de las principales verdades que un cristiano debe saber para conseguir su salvación; impreso en Popayán y reimpreso para uso de las escuelas de primeras letras de esta ciudad (Zizero, 1841).

7. Manual de enseñanza mutua para las escuelas de primeras letras (Triana, 1845). 
8. Libro segundo de máximas morales, novelas i ejemplos instructivos, para la lectura de los niños de primeras letras, escrito por Lorenzo Franza (1851), cura de Barrancas, provincia de Riohacha.

9. Cinco invitaciones hechas al hermano Anselmo Pineda para asistir a las exequias de los cofrades Joaquín Vega y Valerio Barriga, para solemnizar la iniciación de unos profanos y para que coopere a la fundación de una escuela de primeras letras (Anónimo, 1867).

Las expectativas que en torno a la escuela de primeras letras tenía la sociedad neogranadina de finales del siglo XVIII pueden ser aprehendidas a partir del análisis de un documento fundacional de la escuela en Colombia: la Cartilla lacónica de las cuatro reglas de aritmética práctica, dedicada por la Escuela de San Carlos a la Audiencia y Chancillería Real de este Nuevo Reino de Granada - la primera del listado anterior-. A finales del siglo XVIII, en el virreinato de la Nueva Granada, un maestro publicó una cartilla lacónica que pretendía transmitir las reglas básicas de la aritmética, en lo que constituye uno de los primeros registros de los textos escolares colombianos (Boom et al., 1999).

En este texto, Agustín Joseph de Torres (1797: 2) puso como destinatario de su comunicación a la Escuela de Primeras Letras de San Carlos de Santa Fe, movido "(...) por un patriótico celo". Lo que resulta disiente de las motivaciones que el maestro Torres aducía para su ejercicio literario es el patriótico celo, pues en 1797 el concepto de patria empezó a desligarse de la unión con España para lentamente referir el lugar donde se nacía, en lo que Margarita Garrido (1993) Ilamó patriotismo científico y que en otra investigación se ha llamado patriotismo neogranadino para significar:

un conjunto de políticas económicas encaminadas hacia un mejor desenvolvimiento económico del Virreinato, utilizando mejor y más provechosamente sus recursos y su territorio en desmedro de la política mercantilista de España y proponiendo en cambio políticas cercanas a la fisiocracia francesa, con un marcado énfasis en la agricultura y el libre cambio como fuentes de riqueza social (Cárdenas-Herrera, 2011: 92).

Además del celo patriótico, el bien público era otra de las grandes motivaciones que movieron a Torres en 1797 a escribir su cartilla; es decir, a finales del siglo XVIII, las expectativas que este maestro tenía de la escuela de primeras letras estaban dirigidas a alcanzar el bien público y el beneficio de la patria, lo que también se solía llamar felicidad, tres conceptos con un aparente halo etéreo, pero que si se rastrean en los lenguajes políticos de la colonia tardía, se puede observar que tenían un contenido material y concreto, y que, para el caso del cam- 
po educativo, implicaba la expectativa de formar un vasallo útil a los intereses de la corona española.

Así, la escuela de primeras letras tuvo un importante momento en la Nueva Granada a partir de la segunda mitad del siglo XVIII, cuando se produjo la acentuación de las reformas borbónicas (Jaramillo Uribe, 1989). Uno de los hechos más importantes de este proceso fue la fundación de la Escuela de San Carlos en Santa Fe que, movida por patriótico celo, buscaba "[...] que la puerilidad tenga algunos principios de instrucción en beneficio del bien público" (Torres, 1797: 1). Estas escuelas no eran las primeras del virreinato, pero sí las primeras en estar bajo la batuta del gobierno monárquico (Gaitán Bohórquez, 2010).

El concepto primeras letras se usó en informes, testimonios, comunicaciones y solicitudes escritas durante el periodo tardo-colonial: finales del siglo XVIII y comienzos del XIX; por ejemplo, en el informe que el cabildo de Antioquia hizo sobre la creación de escuelas de primeras letras en aquella ciudad (Cabildo de Antioquia, 1790); o la solicitud de Marcos José Ardila (1792), alcalde de Oiba — jurisdicción del Socorro- sobre la necesidad de que se estableciera una escuela de primeras letras en esa parroquia; o el informe desfavorable que sobre Agustín Vidal (1793), maestro de primeras letras de Mompós, se hizo con respecto a sus capacidades y competencias.

Un par de documentos más llaman la atención, cuando se rastrean las huellas del sintagma primeras letras durante la colonia en el AGN de Bogotá: Ofrecimiento servicios al virrey como maestro y Girón: concurso para proveer maestro de escuela; en el primero, Francisco Balvín (1792) ofrecía sus servicios al virrey como maestro de primeras letras para la escuela de la ciudad de Antioquia, y en el segundo, se informaba que el Cabildo de Girón abría concurso, (1794) con el fin de proveer de maestro de primeras letras a la escuela de dicha ciudad. Ambos Ilaman la atención, porque hablan de una publicidad asociada a la enseñanza de las primeras letras en la que tanto los ofertantes de servicios educativos como sus demandantes escribían comunicaciones públicas, en las que daban cuenta de un cierto dinamismo del campo. Al respecto, también se encuentra el testimonio de las fundaciones del Colegio de San Pedro, de escuelas de primeras letras, de obras pías y de beneficencia que hicieron Pedro Martínez de Pinillos (1802) y Manuela Tomasa de la Nájera en Mompós entre 1802 y 1806.

Luego del vacío de poder de 1808, el sintagma primeras letras apareció en catecismos políticos y morales, como los referidos en los numerales 2 y 3 de la lista anterior, y en solicitudes como la elaborada en 1809 por el teniente de gobernador de Nóvita y su cura, que propendían por la fundación de una escuela de primeras letras, apropiando para ello la renta de carnicerías de la población (Anónimo, 1809) —esto sólo algunos meses previos a la declaración de independencia en 1810.

En los meses de incertidumbre que siguieron al vacío de poder de 1808, cuando se habían "roto los lazos que nos unían con la Metrópoli" (Torres Tenorio, 1809), los futuros posibles 
que se abrieron debieron ser muchos, y las incertidumbres seguramente se mezclaron con grandes expectativas, en donde los conceptos de soberanía, independencia y libertad empezaron a posicionarse como prevalentes del lenguaje y de la nueva realidad política. Estas incertidumbres quedaron recogidas en las preguntas que se hizo Camilo Torres Tenorio, en la carta que le escribió a su tío, Ignacio Tenorio (1898: 64), oidor de Quito, el 29 de mayo de 1809 “¿Cuál será entonces nuestra suerte? ¿Qué debemos hacer, qué medidas debemos tomar para sostener nuestra independencia y libertad, esta independencia que debíamos disfrutar desde el mes de septiembre de 1808?".

En esa misma carta, Torres declaraba que las nuevas circunstancias obligaban a ilustrar al pueblo, haciéndole conocer sus derechos sagrados:

\begin{abstract}
Trabajemos, pues, para formar un Cobierno semejante y, si es posible, igual en un todo al de aquellos republicanos [Se refiere al pueblo norteamericano]. Para conseguirlo cultivemos nuestra razón, perfeccionemos nuestras costumbres; porque la razón y las costumbres son en un pueblo libre, lo que las cadenas y los calabozos son en un pueblo esclavo. Sin costumbres privadas, no hay costumbres públicas; y sin estas no puede llegar la sociedad al estado perfecto, que es la libertad. Pero ante todas cosas, ilustremos al pueblo, hagámosle conocer sus derechos sagrados; estos derechos que la tiranía y la esclavitud de tres siglos han sepultado en un abismo, y cuya inquisición sola se ha castigado con las penas más severas hasta el anatema (Torres Tenorio, 1898: 64).
\end{abstract}

\title{
La escuela de primeras letras en la república
}

La república adicionó a la motivación patriótica de finales de la colonia nuevas experiencias y expectativas, muchas de éstas giraban en torno al proceso de construcción republicana y constitución del ciudadano. Estas experiencias y expectativas se convirtieron en la base de las prácticas que constituyeron el campo educativo neogranadino en la primera mitad del siglo XIX.

Para el caso de la escuela de primeras letras republicana, en 1821, con la celebración del Congreso de Cúcuta, se originó el punto de inflexión de la intervención gubernamental en la educación de los niños en Colombia; ${ }^{15}$ fue entonces cuando se ordenó la organización de una escuela de primeras letras en toda villa con más de cien familias, obligando a asistir a ésta a los niños de entre seis y doce años de edad; la financiación corría por cuenta de los vecinos, pero los contenidos y el método de enseñanza los fijó el gobierno republicano (Bushnell, 1984), lo cual no implicó que las comunidades parroquiales obedecieran ciegamente lo que la política pública ordenaba.

${ }^{15}$ De 1819 a 1831, la República de Colombia estuvo conformada por la capitanía general de Venezuela, el virreinato de la Nueva Granada y la audiencia de Quito. 
Además de saber leer y escribir, aritmética y geometría, los niños debían aprender religión, moralidad y los derechos y deberes del hombre en sociedad (El Congreso Jeneral de la República de Colombia, 1822a), como atributos que todo ciudadano debía poseer.

Según la Constitución de 1821, cada cabecera de cantón debía tener una municipalidad, forma del gobierno local, que se denominaría concejo municipal a partir de 1830; esta municipalidad tenía jurisdicción sobre varios pueblos, villas y parroquias que formaban parte de un mismo cantón; sus principales funciones eran la administración de justicia; el aseo y la salubridad de pueblos, villas y ciudades; auxiliar a los jueces políticos en asuntos de orden público; administrar los propios ${ }^{16}$ y arbitrios; velar por el buen estado de caminos, puentes, montes y cultivos del común; promover la agricultura, la industria y el comercio; y fomentar el establecimiento de escuelas de primeras letras (El Congreso Jeneral de la República de Colombia, 1822e).

Tras del triunfo militar sobre tropas españolas, obtenido con la batalla de Boyacá de 1819, y luego de la promulgación de la Constitución de Cúcuta de 1821, el gobierno empezó a ocuparse de forma más decidida de la organización de las escuelas de primeras letras, para lo cual recurrió al sistema de enseñanza mutua de Joseph Lancaster. En estos años, las primeras letras adquirieron un lugar preponderante dentro del lenguaje educativo gubernativo, tal y como lo refieren los Oficios de la Cámara de Representantes al Vicepresidente del Ejecutivo: remisorios de proyectos de ley sobre la destinación del edificio para la escuela de primeras letras en Riohacha en 1824 (Cámara de Representantes de la República de Colombia, 1824).

Pero no sólo el gobierno republicano tomó medidas para establecer nuevas escuelas de primeras letras, también lo hicieron las comunidades parroquiales, como se puede percibir con la representación de 1821 de Fortunato Manuel de Gamba y Valencia (del gobierno y Comandancia General del Chocó) en la cual comunicó al ministro del interior y justicia que, en cumplimiento de los decretos del 20 de mayo y 6 de octubre de 1820, fundó en los corregimientos y los municipios de Quibdó, Babará, Murry, Nóvita y Fado escuelas de primeras letras, y nombró maestros en cada una, pidió que se le permitiera solicitar a los vecinos y padres de familia erigir una casa, o en su defecto, pedir contribuciones para el local de la escuela (Gamba y Valencia, 1821).

También está la representación de Evaristo López, Leonardo Carvallido, Marcelino Antonio Pérez, entre otros, de la municipalidad de Simití (1828), con la que se remitió un memorial en el que solicitaban al secretario del interior, José Manuel Restrepo, la aprobación de un impuesto sobre cada libra de tabaco para costear el establecimiento de escuelas de pri-

\footnotetext{
${ }^{16}$ Eran los ingresos -impuestos- de los que disponía cada parroquia para suplir los gastos de funcionamiento como salarios de funcionarios civiles y militares, renta de los edificios en donde funcionaran instituciones administrativas o militares, reparaciones de los bienes de la parroquia y gastos de operación de la vida burocrática.
} 
meras letras en la ciudad y en los pueblos del cantón. Argumentaban que la subsistencia de las escuelas de primeras letras dependía de una contribución fija e inalterable, por lo que solicitaban la aprobación de dicho impuesto por parte del cuerpo legislativo.

Estos documentos estaban firmados por José Manuel Restrepo (1828a), secretario del interior, quien resolvió comunicar al Congreso de la República, en 1828, la necesidad de emitir un decreto al respecto. Ese mismo año, el secretario del interior remitió varios documentos al presidente, Simón Bolívar, ${ }^{17}$ sobre varios ramos, entre éstos, enviaba uno en el que daba noticia de algunas solicitudes e informes de religiosos; en uno en particular, incluía el sintagma primeras letras a propósito de que fray José María Torres se había enterado del decreto que ordenaba que se estableciera en el convento de Ocaña una escuela de primeras letras y una cátedra de latinidad para los jóvenes de la localidad (Restrepo, 1828b).

Incluso se creó el cargo de ministro de primeras letras, como lo informan los siguientes registros: la certificación de la posesión de J. H. Meléndez como ministro de primeras letras (1820); y una comunicación de Enrique Umaña, intendente de Cundinamarca, quien remitía las solicitudes para el empleo de oficial primero de la Secretaría de Gobierno de Neiva, pedido por el bachiller, Narciso Prieto, oficial segundo de la misma Secretaría, quien acompañaba su solicitud de una comunicación en la que informaba de su experiencia como ministro de primeras letras de la ciudad, quizás como un antecedente que diera cuenta de su trayectoria como funcionario público. ${ }^{18}$

Las expectativas de la república en construcción eran muy altas con respecto al futuro que se abría; y la educación, era uno de los vehículos que las transportaba, prueba de ello es el discurso de la fundación del Colegio de Antioquia en el que su rector, José María Uribe Mondragón (1823: 1), afirmaba: "este edificio [el del Colegio recién fundado] á cuya formación todos los hijos de esta feliz Provincia contribuimos, e va á dar un ser relevante, va a producir hombres ilustrados en quienes el pueblo soberano deposite toda su confianza, para el desempeño de su representación".

En la anterior cita, se pueden verificar varios elementos que se han señalado: a comienzos del periodo republicano, la escuela se financiaba con los fondos que los vecinos proveían; 2) el ideal de conseguir hombres ilustrados, lo que aún se inscribía en el ideal borbónico del Plan de Estudios de Moreno y Escandón; y la intención de formar ciudadanos para la república en cuanto representados implicaba un tipo ideal de ciudadano que debía ser formado en la escuela, conocedor de sus deberes y derechos que, en todo caso, eran sancionados por sus representantes, y no por ellos mismos. Pero, ¿cómo era y qué se esperaba de la escuela en los incipientes años de su estructuración republicana?; en otras palabras, ¿cuál era la

\footnotetext{
${ }^{17}$ Regresó a Bogotá en 1827, y desde entonces, asumió el gobierno de la república hasta 1830.

${ }^{18}$ Congreso Constitucional de la República de Colombia, 1826, Comunicaciones enviadas por la Intendencia, la Prefectura y las Provincias, 1824.
} 
experiencia de escuela y el horizonte de expectativa, el futuro posible que los fundadores de escuelas tenían?, "El será un plantel precioso, cuyas pomposas producciones serán otras tantas columnas, sobre cuya solidez se apoyaran los rasgos más patéticos de la ilustración, patriotismo, religión, humanidad y bellas artes" (Uribe Mondragón, 1823: 1).

Así que el proyecto del heroico Santander, como el rector del Colegio de Antioquia en Medellín solía llamar al vicepresidente colombiano, combinaba religión e ilustración como los fines máximos de la escuela de primeras letras, retomando el concepto colonial de educación que se basaba en la triada: enseñanza, crianza y doctrina, y que se constituía como la base del sistema educativo republicano, antes del Plan de Estudios de Santander de 1826.

En 1823, los fondos para la educación eran aún responsabilidad del público — vecinos—que pedían al dios de los cielos: "Señor: esforzaos pues y contribuid conmigo á esta obra tan digna de los hijos de Antioquia: mirad que no hay un deber tan sagrado para un padre que la educación de un hijo" (Uribe Mondragón, 1823: 13).

De esta forma, los fondos para la escuela eran cosa de la Providencia y de las donaciones de los vecinos, algunos de los cuales, como en el caso del rector del Colegio de Antioquia, se comprometían con la financiación de la escuela como parte de sus nuevos deberes como ciudadano y que la república había traído consigo "Yo trabajaré con un ardor propio de un ciudadano honrado y eclesiástico humano, por aumentarle sus fondos" (Uribe Mondragón, 1823: 13)

\section{Conclusión}

El lenguaje educativo neogranadino sufrió, entre 1767 y 1853, importantes cambios que dan cuenta de un momento de aceleración histórica, en el cual múltiples futuros se abrían como posibilidades reales y en el que grandes cambios se operaban en breves periodos de tiempo. La comprensión histórica del lenguaje educativo, a través del estudio de los usos y los sentidos de los conceptos fundamentales de educación pública, instrucción pública y escuela de primeras letras, permite acceder a las prácticas, las experiencias y las expectativas que los neogranadinos tuvieron en el proceso de transición de colonia a república, en donde la invención de esta última y la constitución del ciudadano se impusieron como las tareas más urgentes del gobierno.

Para acceder a la educación en la colonia, variables como la casta, la riqueza o la condición social se impusieron como argumentos de acceso esenciales, esta situación tendió a cambiar, aunque muy lentamente, a finales del siglo XVIII, particularmente con la acentuación de las reformas borbónicas, que buscaron lograr un mejor desenvolvimiento económico de 
los territorios americanos a partir de la formación de las élites criollas en las ciencias útiles, formación del vasallo útil. ${ }^{19}$

Los debates sobre la escuela de primeras letras, la educación y la instrucción pública aparecieron con más fuerza en la Nueva Granada a finales del siglo XVIII y comienzos del XIX. Uno de los principales retos a los que la escuela de primeras letras trató de responder era el de cómo lograr la transformación del vasallo colonial en ciudadano republicano; la estrategia asumida por agentes del gobierno republicano fue la educación, y dentro de ésta, la difusión de las escuelas de primeras letras era la principal táctica a seguir. Esta asunción de la escuela y la educación como táctica y estrategia para constituir al ciudadano republicano se materializó en la formulación de proyectos, leyes y manuales, dirigidos a lograr la masificación de la educación de los hijos de la patria a través de la educación escolar.

El sintagma primeras letras, durante el periodo de transición de colonia a república, da cuenta del proceso de gubernamentalización de la educación, que implicó la existencia de ministros, pupilos, maestros, manuales, niños y escuelas de primeras letras, vocablos que informan de una suerte de renovación del campo semántico, de los usos y sentidos de voces asociadas al campo educativo, y que sugieren un horizonte de expectativas muy amplio tanto de las autoridades gubernamentales como de las comunidades parroquiales, con respecto al rol que la escuela debía desempeñar en el proceso de invención de la república y de constitución del ciudadano.

De esta forma, en el periodo que comprende las dos últimas décadas del siglo XVIII y la primera mitad del XIX, se transitó de la ilustración del público: la educación de un vasallo útil, entendida como el medio para "reprimir el vicio y abrazar la virtud a contribuir, fomentar la sociedad y abrigar en el seno de su interior las máximas del mejor gobierno" (Finestrad, 2001: 129) a la educación pública: un proceso colectivo de educación moral del ciudadano republicano fuera del ámbito familiar, con dirección del gobierno civilizador y con el fin de alcanzar la tan anhelada civilización del pueblo "Si se quiere moralizar, instruir, enriquecer, es decir, civilizar un pueblo, es de los niños y no de los hombres que de preferencia debe ocuparse el civilizador" (Ospina Rodríguez, 1990: 425).

Con este texto, se quiso mostrar que los cambios en el lenguaje educativo republicano fueron resultado más de contingencias políticas, que intelectuales; es decir, los movimientos sociales y políticos, más que la urgencia de construir una república generó, provocaron una transformación semántica en torno a los vocablos escuela de primeras letras, educación pública e instrucción pública. Es precisamente a la comprensión histórica de los cambios en los usos y sentidos de los conceptos que conformaban el lenguaje educativo neogranadino

19 Para una comprensión más profunda de este tema véase Cárdenas-Herrera (2011). 
a lo que se le ha llamado elementos fundamentales para la historia conceptual de la educación neogranadina.

Además, el presente trabajo apuntó a comprender históricamente el reto que para la población de la Nueva Granada significó la invención de una nueva sociedad, éste se inscribió en un momento de aceleración histórica sin igual, en el que la educación fue considerada, por quienes comandaban la sociedad, como la estrategia fundamental para conseguir la tan anhelada transformación social. Así, el gobierno republicano apostó por la masificación de la educación a través de la fundación de escuelas de primeras letras que tenía la función de construir las bases morales de la república y constituir al ciudadano.

\section{Fuentes}

Archivos

AGN Archivo General de la Nación, Bogotá.

Sección Archivo Anexo, Fondo Instrucción Pública

Sección Colonia, Fondo Miscelánea

Fondo Colegios

Sección República, Fondo Congreso

Fondo Negocios Administrativos

Fondo Solicitudes

BNC Biblioteca Nacional de Colombia, Bogotá.

Fondo Pineda

\section{Documentos}

Anónimo (1867), Cinco invitaciones hechas al hermano Anselmo Pineda para asistir a las exequias de los cofrades Joaquín Vega y Valerio Barriga, para solemnizar la iniciación de unos profanos y para que coopere a la fundación de una escuela de primeras letras, Biblioteca Nacional de Colombia, Fondo Pineda 824, Pieza 6, Bogotá.

Ardila, M. J. (1792), Marcos José Ardila: alcalde de Oiba, jurisdicción del Socorro, representa sobre la necesidad de que se establezca una escuela de primeras letras en esa parroquia, ACN, Sección Colonia, Fondo Miscelánea, folios 33-42, Bogotá..

Balvín, F. (1792), Ofrecimiento servicios al virrey como maestro.

Blanc, L. (1833), La ortografía fijada en la Nueva Granada. Método perfeccionado de enseñanza para las escuelas de primeras letras. AGN, Sección Colonia, Fondo Miscelánea, folios 673-675, Bogotá..

Cabildo de Antioquia (1790), documentos varios.

Cabildo de Girón (1794), Girón: concurso para proveer maestros de escuela , AGN, Sección Colonia, Fondo Colegios, folios 474-487, Bogotá..

Cámara de Representantes de la República de Colombia (1824), Oficios de la Cámara de Representantes al Vicepresidente del Ejecutivo, remisorios de proyectos de ley sobre: Destinación de edificio para escuela de primeras letras en Riohacha. AGN, Sección República, Fondo Congreso, 24, folios: 821-833, Bogotá. 
Franza, L. (1851), Libro segundo de máximas morales, novelas i ejemplos instructivos, para la lectura de los niños de primeras letras, Imprenta de la Unión por Juan Freile, Biblioteca Nacional de Colombia, Fondo Pineda 19, Pieza 2, Bogotá.

Gamba y Valencia, F. M. de, (1821), Sin título, AGn, Sección República, Fondo Negocios Administrativos, folios 901-905, Bogotá.

Martínez de Pinillos, P. (1802), Mompós: fundación de escuelas y colegios, AGN, Sección Colonia, Colegios, 12, 1, D.6, folios 297-339, Bogotá.

Restrepo, J. M. (1828a), Expediente promovido por la municipalidad de Simití por la aprobación de un impuesto, Acn, Sección República, Fondo Peticiones, folios 322-332, Bogotá.

. (1828b), Fray José María Torres queda enterado del Decreto que ordena se establezca en el convento de Ocaña una escuela de primeras letras y una cátedra de latinidad para los jóvenes, AGN, Sección República, Fondo Solicitudes, folios 347-383, Bogotá..

\section{Bibliografía}

Boom, A. M., J. O. Castro y C. E. Noguera (1999), Maestro, escuela y vida cotidiana en Santafé colonial, Sociedad Colombiana de Pedagogía, Bogotá.

Bushnell, D. (1984), El régimen de Santander en la gran Colombia, El Ancora Editores, Bogotá.

Cárdenas-Herrera, J. J. (2015a), La independencia de Colombia: miradas transdisciplinares, Universidad "Antonio Nariño", Bogotá.

(2015b), "Entre la estabilidad económica y la crisis imperial: Nueva Granada 1759-1810", en J.

J. Cárdenas-Herrera y J. Vivas-García (eds.), La independencia de Colombia: miradas transdisciplinares, Universidad "Antonio Nariño", Bogotá.

(2012), "Lenguajes económicos en la prensa neogranadina 1820-1850", en F. A. Ortega y A. Chaparro (eds.), Disfraz y pluma de todos: opinión pública y cultura política, siglos XVIII y XIX, Universidad Nacional de Colombia, Bogotá.

(2011), "La reflexión económica criolla y el patriotismo neogranadino 1759-1810", tesis de maestría, Universidad Nacional de Colombia, Bogotá.

Carlos III (1778) [1984], "Instrucción hecha de orden del Rey nuestro señor para que los Virreyes, Gobernadores, Corregidores, Alcaldes Mayores e Intendentes de provincias en todos los dominios de su Majestad puedan hacer escoger, preparar y enviar a Madrid todas las producciones curiosas de naturaleza que se encontraren en las tierras y pueblos de sus distritos, a fin de que se coloque en el real gabinete de Historia Natural que su Majestad a establecido en esta Corte para beneficio e instrucción pública", en G. Hernández de Alba (comp.), Documentos para la historia de la educación en Colombia, vol. 4, Patronato Colombiano de Artes y Ciencias, Colegio Máximo de las Academias de Colombia-Editorial Kelly, Bogotá, pp. 11-34.

Caruso, M. (2010), "La emancipación semántica: Primeras letras en Hispanoamérica (ca. 1770-1840)", Bordón, Revista de Pedagogía, núm. 62, pp. 39-51.

Congreso Constitucional de la República de Colombia (1826), Comunicaciones enviadas por la Intendencia, la Prefectura y las Provincias, (1824), "Ley sobre organización y arreglo de la Instrucción Pública", en Colección de las leyes dadas por el Congreso Constitucional de la República de Colombia en las sesiones de los años 1825 I 1826, Imprenta de P. Cubides, Bogotá.

Cuervo, R. (1833), Preceptos útiles sobre la conservación de la salud, y la asistencia de los enfermos: mandados imprimir i enseñar en las escuelas de primeras letras de niños de ambos sexos de la Provincia de Bogotá por el Gobernador de ella, Dr. Rufino Cuervo, Imprenta de N. Lora, Bogotá.

Cundinamarca, C. R. y E. (1812), Constitución de la República de Cundinamarca: reformada por el Serenísimo Colegio Revisor y Electoral, Imprenta de Bruno Espinosa de los Monteros, Santa Fe. 
D. J. C. (1812), Catecismo político: arreglado a la constitución de la monarquía española para ilustración del pueblo, instrucción de la juventud y uso de las escuelas de primeras letras por D. J. C., Librería de Arribas, Madrid.

El Congreso Jeneral de la República de Colombia (1822a), "Ley sobre establecimiento de escuelas de primeras letras para los niños de ambos sexos", en Cuerpo de leyes de la República de Colombia, Bruno Espinosa, Bogotá.

(1822b), "Ley sobre establecimiento de colejios ó casas de educación en las Provincias, reforma de las constituciones y planes antiguos y formación de otro nuevo uniforme en toda la República", en Cuerpo de leyes de la República de Colombia, Bruno Espinosa impresor del Gobierno, Bogotá.

(1822c), "Ley sobre aplicación a la enseñanza pública de los bienes de conventos menores", en Cuerpo de leyes de la República de Colombia, Bruno Espinosa impresor del Gobierno, Bogotá. (1822d), "Ley sobre el establecimiento de escuelas de niñas en los conventos de relijiosas", en Cuerpo de leyes de la República de Colombia, Bruno Espinosa impresor del Gobierno, Bogotá.

(1822e), "Ley sobre la organización del régimen político de los departamentos, provincias y cantones en que se divide la república (8 de octubre de 1821)", en Cuerpo de leyes de la República de Colombia, Bruno Espinosa impresor del Gobierno, Bogotá.

Feijoo, B. (1749), Teatro crítico universal, Imprenta de los Herederos de Francisco de Hierro, Madrid.

Fernández, J. (2014), Diccionario político y social del mundo iberoamericano. Iberconceptos II, Universidad del País Vasco-Centro de Estudios Políticos y Constitucionales, Madrid.

Finestrad, F. J. de (2001), El vasallo instruido en el estado del Nuevo Reino de Granada y en sus respectivas obligaciones, Universidad Nacional de Colombia, Bogotá.

Gaitán Bohórquez, J. (2010), "Enlightened programme versus Republican programme in the neogranadian educational", Revista Historia de la Educación Latinoamericana, núm. 14, pp. 100-124.

Garrido, M. (1993), Reclamos y representaciones: variaciones sobre la política en el Nuevo Reino de Granada, 1770-1815, Banco de la República, Bogotá.

Grau, J. (1824), Catecismo político arreglado a la constitución de la República de Colombia, de 30 de agosto de 1821, para el uso de las escuelas de primeras letras del Departamento de Orinoco / por el licenciado José Grau, imprenta de N. Lora, Bogotá.

Jaramillo Uribe, J. (1989), "El proceso de la educación en el virreinato", en A. Tirado Mejía (coord.), Nueva historia de Colombia, Planeta, Bogotá.

Jovellanos, G. M. de (1790), "Borrador de reflexiones sobre la opinión pública (1790-1797)", en G. M. de Jovellanos, Obras completas de Jovellanos, Colección de autores españoles del siglo XVIII, Instituto Feijoo de Estudios del Siglo XVIII, Gijón.

Koselleck, R. (2012), Historias de conceptos: estudios sobre semántica y pragmática del lenguaje político y social, Trotta, Madrid.

(1993), Futuro pasado: para una semántica de los tiempos históricos, Paidós, Barcelona.

Lancaster, J. y L. Institute (1821), The Lancasterian System of Education, with Improvements, the Lancasterian Institute, Baltimore.

Moreno y Escandón, F. A. (1768)[1984], "Proyecto para el establecimiento en la ciudad de Santafé de Bogotá de una Universidad de Estudios Generales, presentado a la Junta General de Aplicaciones por el doctor don Francisco Antonio Moreno y Escandón, Fiscal Protector de Indios, de la Real Audiencia del Nuevo Reino de Granada”, en G. Hernández del Alba (comp.), Documentos para la historia de la educación en Colombia, vol. 4, Patronato Colombiano de Artes y Ciencias, Colegio Máximo de las Academias de Colombia-Editorial Kelly, Bogotá, pp. 26-35.

Ortega, F.; R. O 'Bryen; G. R. Kantaris; J. G. Page; S. Hart; E. Segre; J. M. Barbero; S. L. Morrison; C. Taylor; A. Noble y E. King (2013), "And where are the people? Genealogies of the 'pueblo' during the Late 
Eighteenth and Early Nineteenth Centuries", en G. Kantarys y R. O' Bryen, Latin American Popular Culture Politics, Media, Affect, monografías, A. Boydell \& Brewer, Suffolk.

y. A. Chaparro (2012), Disfraz y pluma de todos: opinión pública y cultura política, siglos XVIII y XIX, Universidad Nacional de Colombia, Bogotá.

Ospina Rodríguez, M. (1990), Antología del pensamiento de Mariano Ospina Rodríguez, Banco de la República, Bogotá.

Padilla, D. (1811), Continuación al N. 15, Imprenta Gubernamental del Gobierno, Bogotá.

Pocock, J. G. A. (2011), Pensamiento político e historia: ensayos sobre teoría y método, Ediciones Akal, Madrid. RAE (Real Academia Española) (2009), Nueva gramática de la lengua española. Morfología y sintaxis, tomo I, Espasa, Madrid.

Redondo, A. (dir.)(1996), La formation de l'enfant en Espagne aux XVle et XVIle siècles: colloque international, Publications de la Sorbonne-Presses de la Sorbonne Nouvelle, París.

Roldán, E. (2014), "Instrucción pública, educación pública y escuela pública: tres conceptos clave en los orígenes de la nación mexicana, 1780-1833”, en A. Martínez Boom y J. Bustamante Vismara (comps.), Escuela pública y maestro en América Latina. Historias de un acontecimiento, siglos XVIII y XIX, Universidad Pedagógica Nacional, Bogotá.

(2013), "Escuela pública: orígenes de un concepto, CA. 1770-1838", ponencia presentada en el XII Congreso Nacional de Investigación Educativa, 11-15 de noviembre, Guanajuato, México.

Torres, A. J. de (1797), Cartilla lacónica de las cuatro reglas de aritmética práctica, dedicada por la Escuela de San Carlos a la Audiencia y Chancillería Real de este Nuevo Reino de Granada, Imprenta patriótica, Santa Fe.

Torres Tenorio, C. (1898), "Carta política a Don Ignacio Tenorio. Oidor de Quito", en C. Torres Tenorio, Documentos históricos, Librería Nueva, Bogotá.

(1809), "Carta política a Don Ignacio Tenorio. Oidor de Quito", en Banco de la República, Proceso histórico del 20 de julio de 1810. Documentos, Banco de la República-Hojas de la Cultura Popular Colombiana, Bogotá.

(1797), Cartilla lacónica de las cuatro reglas de aritmética práctica, dedicada por la Escuela de San Carlos a la Audiencia y Chancillería Real de este Nuevo Reino de Cranada, Imprenta patriótica, Santa Fe.

Triana, J. M. (1845), Manual de enseñanza mutua para las escuelas de primeras letras, Imprenta de J. A. Cualla, Bogotá.

Uribe Mondragón, José J. María M. (1823), Discurso que en la apertura del Colegio de Antioquia de Colombia de nueva creación / pronunció su rector doctor José María Uribe Mondragón, Imprenta del Cobierno por Manuel María Viller Calderón, Medellín.

Recursos electrónicos

Fernández Sebastián, J. y J. F. Fuentes (2007), "Historia conceptual, memoria e identidad. Entrevista a Reinhart Koselleck", Araucaria. Revista Iberoamericana de Filosofía, Políica y Humanidades, Sección Digital, Entrevistas, 2007, abril de 2005, documento html disponible en: <http://institucional.us. es/araucaria/entrevistas/entrevista__.htm> (fecha de consulta: 2/05/16).

RAE (Real Academia Española) (s/f), "Mapa de diccionarios académicos", documentos varios html disponible en: <http://web.frl.es/ntllet/SrvltGUILoginNtlletPub<> (fecha de consulta: 9/12/16).

John Jairo Cárdenas-Herrera. Historiador y magíster en historia de la Universidad Nacional de Colombia. Estudiante del doctorado en ciencias humanas y sociales del Centro de Estudios Sociales (CES) de la Universidad Nacional de Colombia; pasante de Investigación 
en el Institut für Erziehungswissenschaften der Humboldt-Universität zu Berlin (Instituto de Estudios en Educación de la Universidad Humboldt de Berlín). Se ha desempeñado como docente de la Universidad Nacional de Colombia y de la Universidad "Antonio Nariño" en Bogotá. Ha investigado sobre lenguajes económicos y prácticas educativas en el proceso de transición de colonia a república en la Nueva Granada. Publicaciones recientes: CárdenasHerrera (2015), La independencia de Colombia: miradas transdisciplinares; y Cárdenas-Herrera (2012), Disfraz y pluma de todos: opinión pública y cultura política, siglos XVIII y XIX".

Recibido: 30 de enero de 2017.

Aceptado: 29 de marzo de 2017. 